\title{
The effect of dietary supplementation with $\beta-1,3 / 1,6-D$-glucan on stress parameters and meat quality in lambs
}

\author{
J. Sowińska', S. Milewski ${ }^{2}$ Z. Tański ${ }^{2}$, D. Witkowska ${ }^{1,4}$, K. Ząbek², P. Sobiech ${ }^{3}$ and T. Mituniewicz ${ }^{1}$ \\ University of Warmia and Mazury in Olsztyn \\ Faculty of Animal Bioengineering, ${ }^{1}$ Department of Animal and Environmental Hygiene, \\ ${ }^{2}$ Department of Sheep and Goat Breeding, Oczapowskiego 5, 10-719 Olsztyn, Poland \\ ${ }^{3}$ Faculty of Veterinary Medicine, Department of Internal Diseases \\ Oczapowskiego 14, 10-719 Olsztyn, Poland
}

KEY WORDS: $\beta-1,3 / 1,6-D-$ glucan, blood, pre-slaughter handling, meat quality, lambs

Received: $\quad 1$ March 2016

Revised: 3 November 2016

Accepted: 30 December 2016

\footnotetext{
${ }^{4}$ Corresponding author:

e-mail: dorota.witkowska@uwm.edu.pl
}

\begin{abstract}
The study was performed on two groups of lambs: control (CG) and experimental $(E G)$ in which diet was supplemented with Saccharomyces cerevisiae yeast extract. At 100 day of life, 13 lambs from each group were weaned, fasted for $12 \mathrm{~h}$ and, on the following morning, transported to the slaughterhouse. Lambs were weighed and subjected to blood sampling before weaning (blood sampling time (BST 1), before transport (BST 2) and after transport (BST 3). After $24 \mathrm{~h}$ of carcass chilling, ultimate $\mathrm{pH}\left(\mathrm{pH}_{\mathrm{u}}\right)$ and colour were determined in the musculus longissimus dorsi, and muscle samples were collected for water-holding capacity and tenderness analyses. Lambs from experimental group were characterized by higher $(P \leq 0.05)$ body weights after rearing, pre-slaughter starvation and transport. There were no significant differences in haematological parameters induced by the group or BST, except neutrophils to lymphocytes ratio ( $P \leq 0.05$ and $P \leq 0.01$, respectively). Significant differences in cortisol levels were not observed between groups, but significant variations in this parameter were noted between each BST $(P \leq 0.01)$. In both groups, glucose levels increased significantly at BST 3 relative to BST 1 and BST 2; however in EG group the values were higher at each stage in comparison with CG. No significant differences in colour parameters such as $L^{*}$ (lightness) and $b^{*}$ (yellowness) were observed between CG and EG groups. The meat of EG lambs was characterized by lower $(P \leq 0.05)$ values of $\mathrm{pH}_{\mathrm{u}}$, expressed juice area, shear force and colour parameter $a^{*}$ (redness). The results show that $\beta$-glucan reduces the negative impact of pre-slaughter stress on the final product quality.
\end{abstract}

\section{Introduction}

Lamb performance is significantly influenced by pre-slaughter handling, and any negligence during this period can denigrate the accomplishments of the entire rearing process. Pre-slaughter handling involves several procedures that are critical for animal welfare, including pre-slaughter starvation, conditions and duration of transport to the slaughterhouse, loading and unloading of animals (Tadich et al., 2009; Miranda-de la Lama et al., 2010). Weaning is an additional stressor for suckling lambs (Sowińska et al., 2001; Ekiz et al., 2012c). Exposure to all of these factors during a short time 
can exacerbate stress responses in animals, disrupt homeostasis and lower the quantity and quality of the meat (Ekiz et al., 2012a,b,c). Therefore, attempts should be made to limit the number of stress factors and minimize their negative consequences during pre-slaughter handling. The effectiveness of pharmacological agents, herbal preparations, mineral and vitamin supplements in reducing pre-slaughter stress has been investigated in various animal species by many authors (e.g., Ali and Al-Qarawi, 2002; Ali et al., 2006), but very few studies were conducted on lambs. Some agents, such as anti-depressants, may not be used in farm animals to alleviate pre-slaughter stress due to food safety concerns (Ali and Al-Qarawi, 2002; Ali et al., 2006).

The severity of stress is determined by numerous factors which influence biological defence mechanisms and the stress response (Moberg, 2000). Several authors demonstrated that probiotics containing Saccharomyces cerevisiae yeast improved performance and increased humoral and cellular immunity in lambs (Milewski, 2009; Ząbek et al., 2013). Yeast supplements were also found to exert a positive influence on cattle (Dobicki et al., 2005), pigs (Li et al., 2005) and poultry (Zhang et al., 2005). It could be interesting to investigate whether if positive effect of dietary supplementation with the 1,3/1,6-D-glucan might reduce the negative impact of pre-slaughter stress on the final product quality.

The aim of this study was to determine the effect of dietary supplementation with yeast extract containing approximately $70 \%$ of $\beta-1,3 / 1,6$-D-glucan $\left(\right.$ Biolex $^{\circledR}$-Beta $S$ ) on lamb body weight loss, selected blood parameters and meat quality.

\section{Material and methods}

The experiment was approved by the Local Ethics Committee for Animal Experimentation (decision No. 31/2009).

\section{Animals and pre-slaughter handling}

The experiment was conducted on 40 single-born rams, the offsprings of 3-year-old Kamieniecka ewes. The animals were divided into two equal groups based on body weight determined at day 2 of life: $\mathrm{CG}$ - control and EG - experimental group. Throughout the 100-day rearing period, each group of lambs was kept with mothers in separate pens of the same sheep shed. Lambs were fed basal diets composed of hay-silage of grass and legumes, meadow hay, and from day 11 of life - CJ concentrate (commercial feed mixture for lambs; Wipasz, Wadąg, Poland).
The amount of the CJ concentrate was increased every 10 days by $0.05 \mathrm{~kg} /$ animal/day (starting dose $0.05 \mathrm{~kg} /$ animal/day at 11-20 day of life). The diet of EG lambs was supplemented with the Saccharomyces cerevisiae yeast extract (Biolex ${ }^{\circledR}$-Beta S, Leiber Gmbh, Bramsche, Germany) containing approximately $70 \%$ of $\beta-1,3 / 1,6-D$-glucan and was added in the amount of $3 \mathrm{~g} \cdot \mathrm{kg}^{-1}$ of the CJ concentrate.

At the end of the 100-day rearing period, 13 lambs with average body weight were selected from each group, weaned and fasted for $12 \mathrm{~h}$ (with access to water). The groups were kept in separate pens of the same shed with the remaining members of the herd, and they had visual and vocal contact with mothers. On the following morning, lambs were transported to the slaughterhouse in a specialist vehicle with $0.28 \mathrm{~m}^{2}$ floor area per animal in accordance with the provisions of European Council Regulation No. 1/2005 of 22 December 2004 on the protection of animals during transport and related operations. Temperature and humidity inside the vehicle were monitored during transport with the use of LB-520 recorders (Lab-EL, Warsaw, Poland). The average driving speed was $50 \mathrm{~km} \cdot \mathrm{h}^{-1}$, and the duration of transport was $80 \mathrm{~min}$. Approximately $30 \mathrm{~min}$ after unloading, the animals were slaughtered after electrical stunning.

\section{Blood analyses}

Blood samples were collected from the jugular vein three times: before weaning and pre-slaughter fasting (BST 1), before transport (BST 2) and after transport to the slaughterhouse (BST 3). Haematological analyses were performed to determine red blood cell counts (RBC), white blood cell counts (WBC), haemoglobin concentration (HGB), haematocrit (HCT) and the leukocyte profile (leukogram). Basic parameters were determined in the Sysmex haematology analyser (Sysmex America Inc., Lincolnshire, IL, USA). The leukogram and the neutrophil to lymphocyte $(\mathrm{N}: \mathrm{L})$ ratio were determined in Pappenheim stained blood samples.

Serum cortisol and glucose levels were determined in the Cobas Integra 800 biochemical analyser (Roche, Rotkreuz, Switzerland). Cortisol concentrations were measured in a competitive immunoassay with the use of anti-cortisol polyclonal antibodies (Elecsys Cortisol, Roche, Rotkreuz, Switzerland). Glucose levels were determined by the reference enzymatic method with hexokinase. Blood analyses were performed in a specialist laboratory in accordance with the procedures of the Quality Management System (Process 2: Laboratory diagnostics). 
All pre-slaughter handling and blood sampling procedures were performed by the same team of qualified experts. The time of animal manipulation, including catching, weighing and blood sampling in the sheep shed and the slaughterhouse, did not exceed $45 \mathrm{~s}$.

\section{Body weight loss and meat quality}

Lambs were weighed before weaning, before transport and after transport to the slaughterhouse to determine body weight losses in successive stages of pre-slaughter handling. After slaughter, carcasses were chilled for $24 \mathrm{~h}$ at $4{ }^{\circ} \mathrm{C}$. Ultimate $\mathrm{pH}\left(\mathrm{pH}_{\mathrm{u}}\right)$ and colour were determined in the musculus longissimus dorsi, and samples of the muscle were collected for analyses of water-holding capacity and tenderness.

Ultimate $\mathrm{pH}\left(\mathrm{pH}_{\mathrm{u}}\right)$ was measured with the HI 99163 portable meat pH-meter (Hanna Instruments $\mathrm{GmbH}$, Vöhringen, Germany) with the FC 232D electrode. Meat colour was measured in the CIE Lab space ( $L^{*}-$ colour lightness, $a^{*}-$ contribution of redness, $b^{*}$ - contribution of yellowness) by reflectance spectrophotometry with the use of the HunterLab MiniScan XE Plus instrument (Hunterlab, Murnau, Germany), in three replications, at different points along the cross-sectional surface of the muscle. Water-holding capacity (WHC) was determined as the area of expressed juice by the method proposed by Grau and Hamm and modified by Pohja and Niiniwaara (1957). Shear force (SF) was measured in thermally processed meat samples in the Instron 5542 universal testing machine (Instron, Norwood, Canada) equipped with a WarnerBratzler shearing device and a $500 \mathrm{~N}$ load cell
Analyses were performed on cylindrical meat samples with a diameter of $1.27 \mathrm{~cm}$ and a height of $2 \mathrm{~cm}$, prepared in accordance with the method described by Honikel (1998).

\section{Statistical analysis}

The results of body weight loss, selected blood parameters and meat quality parameters (mean $\pm \mathrm{SE}$ ) were analysed statistically in the Statistica 10.0 PL programme (StatSoft Polska, Krakow, Poland). The effects of the yeast extract on body weight loss during pre-slaughter handling and on meat quality parameters were determined by Student's t-test. The influence of dietary supplementation with $\beta-1,3 / 1,6$ D-glucan (group: CG and EG) and blood sampling time (BST 1,2 and 3) on blood parameters was evaluated by two-factor analysis of variance (ANOVA) followed by post-hoc Duncan's test.

\section{Results}

At 7:00 on the day of transport to the slaughterhouse (April), the weather was windless, with ambient temperature of $9.8{ }^{\circ} \mathrm{C}$ and humidity of $65.7 \%$. During the 80-min-long transport, temperature inside the vehicle ranged from 15.9 to $16.4{ }^{\circ} \mathrm{C}$ and relative humidity - from $70.5 \%$ to $82.3 \%$.

\section{Body weight and body weight loss}

Lambs from the experimental group were characterized by higher $(P \leq 0.05)$ average body weight before weaning and pre-slaughter fasting, before transport and after transport in comparison with CG animals (Table 1). Percentage body weight loss did not differ between groups.

Table 1. Body weight of lambs and body weight losses during pre-slaughter handling (mean $\pm \mathrm{SE}$ )

\begin{tabular}{|c|c|c|c|c|}
\hline \multirow{3}{*}{ Indices } & \multicolumn{4}{|c|}{ Group of lambs } \\
\hline & \multicolumn{2}{|c|}{ control } & \multicolumn{2}{|c|}{ experimental } \\
\hline & mean & SE & mean & SE \\
\hline Body weight before weaning and pre-slaughter starvation, $\mathrm{kg}$ & $25.16^{b}$ & 1.00 & $29.10^{\mathrm{a}}$ & 1.19 \\
\hline Body weight before transport, $\mathrm{kg}$ & $24.00^{\mathrm{b}}$ & 0.99 & $28.23^{\mathrm{a}}$ & 1.11 \\
\hline Body weight after transport, kg & $23.41^{\mathrm{b}}$ & 1.15 & $27.65^{\mathrm{a}}$ & 1.03 \\
\hline \multicolumn{5}{|l|}{ Body weight losses during pre-slaughter starvation } \\
\hline $\mathrm{kg}$ & 1.16 & 0.17 & 0.88 & 0.21 \\
\hline$\%$ & 4.61 & 0.65 & 2.95 & 0.63 \\
\hline \multicolumn{5}{|l|}{ Body weight losses during transport } \\
\hline $\mathrm{kg}$ & 0.59 & 0.16 & 0.66 & 0.10 \\
\hline$\%$ & 2.67 & 0.82 & 2.22 & 0.36 \\
\hline \multicolumn{5}{|l|}{ Total body weight losses during pre-slaughter handling, } \\
\hline $\mathrm{kg}$ & 1.66 & 0.20 & 1.54 & 0.24 \\
\hline$\%$ & 7.19 & 1.05 & 5.16 & 0.66 \\
\hline
\end{tabular}

${ }^{\text {ab }}$ - means with different superscripts within a row are significantly different at $P \leq 0.05$ according to Student's t-test 
Table 2. The effect of blood sampling time and group of lambs on blood parameters (mean \pm SE)

\begin{tabular}{|c|c|c|c|c|c|c|c|c|c|}
\hline \multirow{3}{*}{ Indices $^{1}$} & \multicolumn{6}{|c|}{ Group of lambs (GL) } & \multirow{2}{*}{\multicolumn{3}{|c|}{$\begin{array}{l}\text { Significance } \\
P \text {-value } \\
\underline{P}\end{array}$}} \\
\hline & \multicolumn{3}{|c|}{ control (CG) } & \multicolumn{3}{|c|}{ experimental (EG) } & & & \\
\hline & CG-BST $1^{2}$ & CG-BST 2 & CG-BST 3 & EG-BST 1 & EG-BST 2 & EG-BST 3 & $\overline{\mathrm{GL}}$ & BST & GL x BST \\
\hline $\mathrm{RBC}, 10^{12} \cdot \mathrm{l}^{-1}$ & $8.86 \pm 0.32$ & $9.10 \pm 0.31$ & $8.26 \pm 0.24$ & $9.42 \pm 0.31$ & $9.21 \pm 0.23$ & $8.89 \pm 0.31$ & NS & NS & NS \\
\hline WBC, $10^{9} \cdot I^{-1}$ & $9.61 \pm 0.46$ & $10.31 \pm 0.56$ & $9.82 \pm 0.49$ & $11.67 \pm 0.90$ & $10.05 \pm 0.34$ & $11.12 \pm 0.52$ & NS & NS & NS \\
\hline $\mathrm{HGB}, \mathrm{mmol} \cdot \mathrm{I}^{-1}$ & $7.35 \pm 0.23$ & $7.24 \pm 0.26$ & $6.35 \pm 0.18$ & $7.87 \pm 0.16$ & $7.66 \pm 0.16$ & $6.86 \pm 0.14$ & NS & NS & NS \\
\hline $\mathrm{HCT}, \mathrm{I} \cdot \mathrm{I}^{-1}$ & $0.35 \pm 0.02$ & $0.36 \pm 0.01$ & $0.34 \pm 0.01$ & $0.37 \pm 0.02$ & $0.39 \pm 0.01$ & $0.36 \pm 0.02$ & NS & NS & NS \\
\hline$N$ : L ratio & $0.35 \pm 0.06^{A}$ & $0.51 \pm 0.10^{B}$ & $0.61 \pm 0.07^{c}$ & $0.25 \pm 0.06^{A}$ & $0.34 \pm 0.03^{A}$ & $0.40 \pm 0.06^{B}$ & * & ** & NS \\
\hline \multicolumn{10}{|c|}{ Cortisol concentration, } \\
\hline $\mathrm{nmol} \cdot \mathrm{I}^{-1}$ & $7.73 \pm 0.83^{A}$ & $17.11 \pm 3.59 c$ & $61.83 \pm 4.4^{\mathrm{E}}$ & $5.52 \pm 2.21^{A}$ & $9.94 \pm 3.86^{B}$ & $37.26 \pm 4.14^{\mathrm{D}}$ & NS & $* *$ & NS \\
\hline \multicolumn{10}{|c|}{ Glucose concentration, } \\
\hline $\mathrm{mmol} \cdot \mathrm{I}^{-1}$ & $3.51 \pm 0.19^{A}$ & $3.42 \pm 0.14^{\mathrm{A}}$ & $5.39 \pm 0.39^{D}$ & $4.20 \pm 0.16^{\mathrm{B}}$ & $3.98 \pm 0.15^{\mathrm{B}}$ & $5.12 \pm 0.38^{\mathrm{CD}}$ & ** & $* *$ & NS \\
\hline
\end{tabular}

${ }^{1}$ RBC - red blood cells count; WBC - white blood cells count; HGB - haemoglobin concentration; HCT - haematocrit; $N$ : $L$ ratio - neutrophils to leucocytes ratio; ${ }^{2}$ BST (blood sampling time): BST 1 - before weaning, BST 2 - before transport, BST 3 - after transport; ${ }^{3}$ significance of main effects and their interaction according to two-way ANOVA test at $P \leq 0.05\left(^{*}\right)$ or $P \leq 0.01\left(^{* *}\right)$ followed by Ducan's test with means with different superscripts ( ${ }^{A B C D E}$ ) within a row significantly different at $P \leq 0.05$; NS - not significant

\section{Blood parameters}

Haematological parameters: RBC, WBC, HBC and HCT did not differ significantly between groups or between each BST (Table 2). The average values of the N:L ratio was influenced by the lamb group and BST (higher ratio was in CG lambs at BST 2 and BST 3). N:L ratio increased in successive stages of pre-slaughter handling in CG (CG-BST $1<$ CGBST $2<$ CG-BST 3), but in EG a statistically significant difference was noted only between BST 1 or BST 2 and BST $3(P \leq 0.05$ for both EG-BST 1 vs EG-BST 3 and EG-BST 2 vs EG-BST 3); EG-BST 1 and EG-BST 2 did not differ.

Significant differences in cortisol levels were not observed between animal groups, whereas BST induced significant variations in this parameter regardless of the group (Table 2). The plasma cortisol level was systematically increased in successive stages of pre-slaughter handling and was the highest after transport to the slaughterhouse (BST $3>$ BST $2>$ BST 1 for both groups).

Serum glucose levels varied significantly between groups and BST (Table 2). Glucose concentration at BST 1 and BST 2 was significantly higher in than EG. In each group, glucose concentration did not differ significantly between BST 1 and BST 2, but a significant increase in this parameter was noted at BST 3 in comparison with BST 1 and BST 2 $(P \leq 0.01$ for CG-BST 3 vs CG-BST 1, CG-BST 3 vs CG-BST 2, EG-BST 3 vs EG-BST 1 and EGBST 3 vs EG-BST 2).

\section{Meat quality}

In comparison with the meat of CG lambs, the meat of EG lambs was characterized with significantly $(P \leq 0.05)$ lower values of $\mathrm{pH}_{\mathrm{u}}$, expressed juice area, shear force and contribution of redness $a^{*}$ (Table 3). No significant differences in colour lightness $L^{*}$ and contribution of yellowness $b^{*}$ were observed between groups.

Table 3. Lamb meat quality characteristics (mean \pm SE)

\begin{tabular}{|c|c|c|c|c|}
\hline \multirow{3}{*}{ Specification } & \multicolumn{4}{|c|}{ Group of lambs } \\
\hline & \multicolumn{2}{|c|}{ control } & \multicolumn{2}{|c|}{ experimental } \\
\hline & mean & SE & mean & SE \\
\hline $\mathrm{pH}_{u}$ & $5.76^{a}$ & 0.01 & $5.62^{b}$ & 0.02 \\
\hline \multicolumn{5}{|c|}{ Colour parameters ${ }^{1}$} \\
\hline$L^{*}$ & 46.50 & 0.91 & 47.67 & 0.51 \\
\hline$a^{*}$ & $12.17^{a}$ & 0.18 & $10.78^{b}$ & 0.28 \\
\hline$b^{*}$ & 14.34 & 0.31 & 14.45 & 0.23 \\
\hline $\mathrm{WHC}^{2}, \mathrm{~cm}^{2}$ & $18.92^{\mathrm{a}}$ & 0.88 & $16.44^{b}$ & 0.55 \\
\hline Shear force, $\mathrm{N}$ & $26.52^{\mathrm{a}}$ & 1.74 & $23.58^{b}$ & 2.20 \\
\hline
\end{tabular}

${ }^{1} L^{*}$ - lightness; $a^{*}$ - redness; $b^{*}$ - yellowness; ${ }^{2} \mathrm{WHC}$ - water-holding capacity; ${ }^{\text {ab }}$ - means with different superscripts within a row are significantly different at $P \leq 0.05$ according to Student's t-test

\section{Discussion}

Body weight loss. In other studies, lambs (Milewski, 2009; Ząbek et al., 2013) and calves (Dobicki et al., 2005) fed diets supplemented with $\beta$-glucan were also characterized by significantly higher body weights at weaning. The cited authors attributed the noted improvements in performance parameters to the prebiotic properties and immunostimulating effects of dried yeast extract which could have improved the health status of the animals.

Body weight losses have been investigated in small ruminants that differed in age, breed, duration of transport and pre-slaughter fasting (Hall et al., 1997; Kadim et al., 2006; De la Fuente et al., 2010), 
but the results remain inconclusive. Del la Fuente et al. (2010) did not observe body weight losses in 40-dayold suckling lambs transported for $30 \mathrm{~min}$ or $5 \mathrm{~h}$ after weaning. The remaining authors reported body weight losses of $5.7-8.0 \%$ regardless of the duration of transport or pre-slaughter starvation. Hall et al. (1997) noted high individual differences in body weight loss in sheep confined in a locked and immobilized trailer for $14 \mathrm{~h}$, where animals with lower initial body weight where characterized by higher percentage body weight loss. The body weight losses noted during pre-slaughter handling in this study (6.66-7.19\%) are within the range of values given by the cited authors, however no statistical difference between examined and control group was observed in this study.

Blood parameters. Stress factors activate the hypothalamic-pituitary-adrenal (HPA) axis and induce changes in haematological, biochemical and hormonal blood parameters. Prolonged stress can compromise cellular and humoral immunity and disrupt metabolic processes (Ali et al., 2006; Bórnez et al., 2009; Tadich et al., 2009; Miranda-de la Lama et al., 2010; Ekiz et al., 2012a,b).

Milewski (2009) reported significantly higher RBC and HGB counts in lambs fed diet with dried yeast extract addition during rearing. The beneficial influence of yeast extracts on RBC, HGB and HCT values in calves was demonstrated by Dobicki et al. (2005). Milewski (2009) also noted a significant increase $(P \leq 0.01)$ in the percentage of lymphocytes and a tendency towards a lower percentage of neutrophils in the blood of lambs fed diet with dried yeast addition. More recent studies revealed that both dried brewer's yeast (Milewski et al., 2013) and $\beta-1,3 / 1,6-D$-glucan (Ząbek et al., 2013) stimulated immune responses in lambs. These authors concluded that dietary supplementation with yeast extracts improves the immune status of animals. In our study, no significant differences in the average values of RBC, HGB and HCT were observed between group of lambs or between each BST. A decrease in the $\mathrm{N}: \mathrm{L}$ ratio was observed in lambs fed diets supplemented with $\beta-1,3 / 1,6-\mathrm{D}$-glucan.

The values of RBC, WBC, HGB and HCT did not differ significantly between blood sampling times, which is consistent with the results of other studies. Ekiz et al. (2012a) did not observe significant differences in the haematological parameters of lambs after $75 \mathrm{~min}$ of transport in comparison with a base level. Bórnez et al. (2009) also reported an absence of significant variations in RBC, HCT and HGB values in 30-day-old and 70-day-old lambs after $30 \mathrm{~min}$ of transport. Ali et al. (2006) did not observe signifi- cant differences in HCT or HGB in lambs after $2 \mathrm{~h}$ of transport. Tadich et al. (2009) did not report significant differences in the HCT values of 70-day-old lambs between blood sampling times: before transport, after $48 \mathrm{~h}$ of transport, after $10 \mathrm{~h}$ of rest, and during slaughter.

In the present study, the increased $\mathrm{N}$ : L ratio was determined in both groups of animals after weaning (BST 2) and after transport to the slaughterhouse (BST 3) in comparison with the value noted before weaning (BST 1). There was found 1.7-fold increase of $\mathrm{N}$ : L ratio in CG and only 1.5-fold in EG throughout pre-slaughter handling, relative to BST 1.

Stressors increase the percentage of neutrophils and decrease the percentage of lymphocytes in the leukogram, which leads to changes in the $\mathrm{N}: \mathrm{L}$ ratio (Schaefer et al., 1997). For this reason, the $\mathrm{N}: \mathrm{L}$ ratio is regarded as an important indicator of stress response in animals (Miranda-de la Lama et al., 2010; Ekiz et al., 2012a,b). The influence of various stressors on the value of the $\mathrm{N}$ : L ratio was studied by many authors. Miranda-de la Lama et al. (2010) observed the increased $\mathrm{N}$ : L ratio in lambs in response to prolonged confinement before slaughter as well as high ambient temperatures. Ekiz et al. (2012b) did not report significant correlations between the $\mathrm{N}: \mathrm{L}$ ratio in lambs and age at weaning. In another study, these authors (Ekiz et al., 2012a) noted a significant increase in the $\mathrm{N}$ : L ratio in 135-day-old rams after $75 \mathrm{~min}$ of transport to the slaughterhouse. In our study, pre-slaughter handling was also stressful, but the values of the $N$ : L ratio and its increase in successive stages of pre-slaughter handling were lower in EG than in CG lambs. Our findings could indicate that lambs whose diets were supplemented with $\beta$-glucan are less susceptible to stress.

No significant differences in cortisol levels were observed between groups of lambs, whereas BST highly significantly differentiated the examined parameter regardless of group. The observed response of the HPA axis confirms that pre-slaughter handling is stressful. Cortisol is a reliable indicator of stress in animals (Ali et al., 2006; Kadim et al., 2009). In the present experiment, during successive stages of pre-slaughter handling, cortisol concentrations were increased in both groups and were the highest after transport to the slaughterhouse. During the entire period of pre-slaughter handling, the 8-fold increase of serum cortisol levels in CG and only 6.7-fold in EG, relative to BST 1 values were found. These results suggest that $\beta-1,3 / 1,6-\mathrm{D}$-glucan minimizes stress, and validate the observations made based on the values of the $\mathrm{N}: \mathrm{L}$ ratio. 
In lambs the stress associated with pre-slaughter handling (including weaning, pre-slaughter starvation and pre-slaughter rest in the lairage), conditions and duration of transport, as well as season has been studied extensively (Sowińska et al., 2001; Fisher et al., 2005; Ali et al., 2006; Kadim et al., 2006, 2009; Bórnez et al., 2009; Tadich et al., 2009; Miranda-de la Lama et al., 2010; Ekiz et al., 2012a,b). Increased blood cortisol levels in lambs after $75 \mathrm{~min}$ (Ekiz et al., 2012a), 2 h (Ali et al., 2006) and 48 h of transport (Tadich et al., 2009) indicate that transport is the most significant stressor during pre-slaughter handling.

Serum glucose levels differed highly significantly between groups and BST. At BST 1 and BST 2, significantly higher glucose concentrations were noted in EG lambs than in CG animals. A highly significant increase in serum glucose levels was noted in both CG and EG lambs at BST 3 relative to BST 1 and BST 2, which indicates that both weaning and transport are highly stressful for lambs. It should be noted, however, that throughout pre-slaughter handling, 1.5 -fold increase of glucose concentrations in CG lambs, and only 1.2-fold in EG animals relative to the base value were determined. These findings, combined with serum cortisol levels and $\mathrm{N}$ : L ratio values, could suggest that lambs fed diets supplemented with $\beta-1,3 / 1,6-\mathrm{D}$-glucan are less susceptible to stress.

Changes in blood glucose levels of lambs in response to pre-slaughter stress were also observed by other authors (Ali et al., 2006; Bórnez et al., 2009; Tadich et al., 2009; Ekiz et al., 2012a). Ali et al. (2006) reported a significant increase $(P \leq 0.05)$ in glucose concentrations after a 2-hour transport. According to the cited authors, stress-induced hyperglycaemia could result from hypercortisolaemia or intensified glucose production in the liver, which points to stimulation of the sympathetic-adrenomedullary system. In the study by Ekiz et al. (2012a), glucose levels in lambs also increased significantly after $75 \mathrm{~min}$ of transport. In lambs that rested for $30 \mathrm{~min}$ after transport, glucose levels continued to increase until slaughter, whereas in individuals that rested for $18 \mathrm{~h}$, glucose levels were similar to those noted immediately after transport. Tadich et al. (2009) observed similar glucose concentrations in lambs remaining in the farm and after $48 \mathrm{~h}$ of transport, which could suggest that animal handling before transport, including weaning and catching, could be more stressful than transport itself.

The results of this study and the findings of other authors indicate that even under optimal conditions, animals are exposed to numerous physical, physiological and psychological stressors that decrease their welfare and deplete their bodily reserves. Their welfare is influenced by the duration of transport, age at weaning, pre-slaughter rest and its duration.

Only Ali et al. (2006) studied the reduction of transport-induced stress in lambs. They found significantly higher HCT values and lymphocyte counts and significantly lower cortisol and glucose concentrations in lambs that had been administered xylazine before 2-hour transport in comparison with the control group. According to the cited authors, xylazine is an effective stress-reducing agent. Our findings suggest that dietary supplementation with $\beta-1,3 / 1,6-\mathrm{D}$-glucan could also alleviate stress in lambs during pre-slaughter handling.

Meat quality. The influence of pre-slaughter stress has been studied extensively for reasons of production profitability and animal welfare. Preslaughter stressors disrupt metabolic processes, which could have an adverse influence on meat quality (Apple et al., 1995; Kadim et al., 2009; Ekiz et al., 2012a).

In our study, the meat of EG lambs was characterized by significantly lower values of $\mathrm{pH}_{\mathrm{u}}, \mathrm{WHC}$, SF and contribution of redness $a^{*}$, compared with the meat of CG lambs. Ultimate $\mathrm{pH}$ is a key determinant of meat quality which affects the water-holding capacity, colour and tenderness of meat. The value of $\mathrm{pH}_{\mathrm{u}}$ is determined by a combination of factors during pre-slaughter handling which influence muscle glycogen levels and glycolysis rate (Gregory, 1998). Pre-slaughter stress depletes glycogen reserves in muscles, which contributes to their insufficient acidification after slaughter, followed by an increase in the pH of meat (Apple et al., 1995; Kannan et al., 2003). The results of many studies demonstrated that stress factors significantly influence $\mathrm{pH}_{\mathrm{u}}$ values. Kadim et al. (2006) observed that a 2-hour transport significantly influenced ultimate $\mathrm{pH}$ values in goats. In another study, Kadim et al. (2009) found higher $\mathrm{pH}_{u}$ values in lambs slaughtered after $3 \mathrm{~h}$ of transport in comparison with animals that were not transported. Apple et al. (2005) demonstrated that immobilization stress in sheep significantly increased the $\mathrm{pH}_{\mathrm{u}}$ values of meat. In lambs transported for $4 \mathrm{~h}$ on an uneven road, the ultimate acidity of meat increased significantly in comparison with lambs transported on a smooth road (Ruiz-de la Torre et al., 2001). In this study, the average value of $\mathrm{pH}_{\mathrm{u}}$ was higher in $\mathrm{CG}$ lambs. Ultimate $\mathrm{pH}$ ranged from 5.5 to 5.8 in both groups, which points to the 
high quality of meat in both control and experimental lambs. Lower values of $\mathrm{pH}_{u}$ in EG could suggest that dietary supplementation with $\beta-1,3 / 1,6$-D-glucan minimizes stress responses in lambs.

The meat of CG lambs (with higher $\mathrm{pH}_{\mathrm{u}}$ ) was characterized by a significantly larger area of expressed juice $\left(\mathrm{cm}^{2}\right)$ and higher shear force. Similar results were reported by Bond et al. (2004) who found significantly higher areas of expressed juice and ultimate $\mathrm{pH}$ in the meat of stressed lambs. Kadim et al. (2009) demonstrated that the meat of 12-month-old lambs was characterized by a significantly smaller area of expressed juice after $3 \mathrm{~h}$ of transport in comparison with animals that were not transported. In contrast, stress did not influence the water-holding capacity of goat meat in the study of Kannan et al. (2003).

In our study, the meat of CG lambs was characterized by higher shear force and greater hardness than the meat of animals fed the yeast extract. Zhang et al. (2005) demonstrated that dietary supplementation with Saccharomyces cerevisiae yeast increased the tenderness of turkey meat. Many authors found that pre-slaughter stress can exert a negative influence on meat tenderness. In a study by Kadim et al. (2009), the meat of sheep transported for $3 \mathrm{~h}$ was characterized by significantly higher shear force than the meat of animals from control group. Similar results were reported in goats after $2 \mathrm{~h}$ of transport (Kadim et al., 2006) and in lambs which were slaughtered after 75 min of transport and a short rest period (Ekiz et al., 2012a). In contrast, Apple et al. (1995) reported lower shear force values in the meat of lambs subjected to pre-slaughter stress in comparison with the control group, whereas Kannan et al. (2003) did not report any differences in the hardness of meat from transported and non-transported goats.

In the present study, colour lightness $L^{*}$ and contribution of yellowness $b^{*}$ were similar in both groups of animals. Significantly higher contribution of redness $a^{*}$ was noted in CG, which could be attributed to the higher $\mathrm{pH}_{\mathrm{u}}$ values of meat in this group.

Pre-slaughter stress can adversely influence the colour of meat and, consequently, decrease consumer acceptance of the product (Gregory, 1998; Ekiz et al., 2012a). Many authors demonstrated that stressors contribute to a darker colour of lamb meat (Apple et al., 1995; Bond et al., 2004). According to Ruiz-de la Torre et al. (2001), the contribution of redness increased in the meat of 10- to 12-week-old lambs transported on an uneven road. Higher values of parameter $a^{*}$ were also reported by Sañudo et al.
(1998) in the meat of weaned lambs in comparison with lambs that were not separated from their mothers. Kadim et al. (2006) observed that the meat of goats was darker and characterized by higher contribution of redness and lower contribution of yellowness (lower values of $L^{*}$ and $b^{*}$, higher values of $a^{*}$ ) after $2 \mathrm{~h}$ of transport in comparison with the meat of non-transported animals. Similar results were reported by Kannan et al. (2003) in a study on goats. In a study by Kadim et al. (2009), transport had no significant influence on the colour parameters of lamb meat. Ekiz et al. (2012a) did not observe significant differences in the colour parameters of lamb meat regardless of pre-slaughter handling (transport, no transport, duration of pre-slaughter rest).

\section{Conclusions}

Our findings indicate that the supplementation of animal diets with Saccharomyces cerevisiae yeast could alleviate stress responses before slaughter. The yeast addition into diet also significantly improved the water-holding capacity and tenderness of meat. Supplementation of yeast rich in $\beta-1,3 / 1,6-$ D-glucan into diet enhances immunity and reduces the negative impact of pre-slaughter stress on the final quality of lambs product.

\section{References}

Ali B.H., Al-Qarawi A.A., 2002. Evaluation of drugs used in the control of stressful stimuli in domestic animals: a review. Acta Vet. Brno 71, 205-216, https://doi.org/10.2754/avb200271020205

Ali B.H., Al-Qarawi A.A., Mousa H.M., 2006. Stress associated with road transportation in desert sheep and goats, and the effect of pretreatment with xylazine or sodium betaine. Res. Vet. Sci. 80, 343-348, https://doi.org/10.1016/j.rvsc.2005.07.012

Apple J.K., Dikeman M.E., Minton J.E., McMurphy R.M., Fedde M.R., Leith D.E., Unruh J.A., 1995. Effects of restraint and isolation stress and epidural blockade on endocrine and blood metabolite stress, muscle glycogen metabolism, and incidence of dark-cutting longissimus muscle of sheep. J. Anim. Sci. 73, 2295-2307, https://doi.org/10.2527/1995.7382295x

Bórnez R., Linares M.B., Vergara H., 2009. Haematological, hormonal and biochemical blood parameters in lambs: Effect of age and blood sampling time. Livest. Sci. 121, 200-206, https://doi. org/10.1016/j.livsci.2008.06.009

Bond J.J., Can L.A., Warner R.D., 2004. The effect of exercise stress, adrenaline injection and electrical stimulation on changes in quality attributes and proteins in Semimembranosus muscle of lamb. Meat Sci. 68, 469-477, https://doi.org/10.1016/j. meatsci.2004.05.001

De la Fuente J., Sánchez M., Pérez C., Lauzurica S., Vieira C., Gonzáles de Chávarri E., Díaz M.T., 2010. Physiological response and carcass and meat quality of suckling lambs in relation to transport time and stocking density during transport by road. Animal 4, 250-258, https://doi.org/10.1017/S1751731109991108 
Dobicki A., Preś J., Łuczak W., Szyrner A., 2005. Influence of dried brewery's yeast on body weight gains, physiological and biochemical indicators of blood and development of the rumen micro-organisms in calves (in Polish). Med. Wet. 61, 946-949

Ekiz B., Ekiz E.E., Kocak O., Yalcintan H., Yilmaz A., 2012a. Effect of pre-slaughter management regarding transportation and time in lairage on certain stress parameters, carcass and meat quality characteristics in Kivircik lambs. Meat Sci. 90, 967-976, https://doi.org/10.1016/j.meatsci.2011.11.042

Ekiz B., Ekiz E.E., Yalcintan H., Kocak O., Yilmaz A., 2012b. Effects of suckling length $(45,75$ and $120 \mathrm{~d})$ and rearing type on cortisol level, carcass and meat quality characteristics in Kivircik lambs. Meat Sci. 92, 53-61, https://doi.org/10.1016/j. meatsci.2012.04.006

Ekiz B., Yilmaz A., Ozcan M., Kocak O., 2012c. Effect of production system on carcass measurements and meat quality of Kivircik lambs. Meat Sci. 90, 465-471, https://doi.org/10.1016/j.meatsci.2011.09.008

Fisher A.D., Stewart M., Duganzich D.M., Tacon J., Matthews L.R., 2005. The effects of stationary periods and external temperature and humidity on thermal stress conditions within sheep transport vehicles. N. Z. Vet. J. 53, 6-9, https://doi. org/10.1080/00480169.2005.36461

Gregory N.G., 1998. Animal Welfare and Meat Science. CABI Publishing. Wallingford (UK)

Hall S.J.G., Schmidt B., Broom D.M., 1997. Feeding behavior and the intake of food and water by sheep after a period of deprivation lasting 14 h. Anim. Sci. 64, 105-110, https://doi.org/10.1017/ S1357729800015605

Honikel K.O., 1998. Reference methods for the assessment of physical characteristics of meat. Meat Sci. 49, 447-457, https://doi. org/10.1016/S0309-1740(98)00034-5

Kadim I.T., Mahgoub A., Al-Kindi A., Al-Marzooqi W., Al-Saqri N.M., 2006. Effects of transportation at high ambient temperatures on physiological responses, carcass and meat quality characteristics of three breeds of Omani goats. Meat Sci. 73, 626-634, https://doi.org/10.1016/j.meatsci.2006.03.003

Kadim I.T., Mahgoub O., Al-Marzooqi W., Khalaf S., Al-Sinawi S.S.H., Al-Amri I.S., 2009. Effects of transportation during the hot season and low voltage electrical stimulation on histochemical and meat quality characteristics of sheep longissimus muscle. Livest. Sci. 126, 154-161, https://doi.org/10.1016/j. livsci.2009.06.014

Kannan G., Kouakou B., Terrill T.H., Gelaye S., 2003. Endocrine, blood metabolite, and meat quality changes in goats as influenced by short-term, preslaughter stress. J. Anim. Sci. 81, 1499-1507, https://doi.org/10.2527/2003.8161499x

Li J., Xing J., Li D.D., Wang X., Zhao L., Lv S., Huang D., 2005. Effects of $\beta$-glucan extracted from Saccharomyces cerevisiae on humoral and cellular immunity in weaned piglets. Arch. Anim. Nutr. 59, 303-312, https://doi.org/10.1080/17450390500247832
Milewski S., 2009. Effect of yeast preparations Saccharomyces cerevisiae on meat performance traits and blood hematological indices in sucking lambs (in Polish). Med. Wet. 65, 51-54

Milewski S., Wójcik R., Zaleska B., Małaczewska J., Tański Z., Siwicki A.K., 2013. Effect of Saccharomyces cerevisiae dried yeast on the meat performance traits and selected indicators of humoral immunity in lambs. Acta Vet. Brno 82, 147-151, https://doi.org/10.2754/avb201382020147

Miranda-de la Lama G.C., Rivero L., Chacón G., Garcia-Belenguer S., Villarroel M., Maria G.A., 2010. Effect of the pre-slaughter logistic chain on some indicators of welfare in lambs. Livest. Sci. 128, 52-59, https://doi.org/10.1016/j.livsci.2009.10.013

Moberg G.P., 2000. Biological response to stress: implication for animal welfare. In: G.P. Moberg, J.A. Mench (Editors). The Biology of Animal Stress: Basic Principles and Implications for Animal Welfare. CABI Publishing. Wallingford (UK), pp. 1-22, https:// doi.org/10.1079/9780851993591.0001

Pohja M.S., Niinivaara F.P., 1957. Die Bestimmung der Wasserbindung des Fleisches mittels der Konstantdruckmethode. Fleischwirtschaft 9, 193-195

Ruiz-de-la-Torre J.L., Velarde A., Manteca X., Diestre A., Gispert M., Hall S.J.G., Broom D.M., 2001. Effects of vehicle movements during transport on the stress responses and meat quality of sheep. Vet. Rec. 148, 227-229, https://doi.org/10.1136/ vr.148.8.227

Sañudo C., Sierra I., Olleta J.L., Martin L., Campo M.M., Santolaria P., Wood D.J., Nute G.R., 1998. Influence of weaning on carcass quality, fatty acid composition and meat quality in intensive lamb production systems. Anim. Sci. 66, 175-187, https://doi. org/10.1017/S1357729800008948

Schaefer A.L., Jones S.D., Stanley R.W., 1997. The use of electrolyte solutions for reducing transport stress. J. Anim. Sci. 75, 258-265, https://doi.org/10.2527/1997.751258x

Sowińska J., Brzostowski H., Tański Z., Czaja K., 2001. The weaning stress response in lambs of different age. Czech J. Anim. Sci. 46, 465-468

Tadich N., Gallo C., Brito M.L., Broom D.M., 2009. Effects of weaning and $48 \mathrm{~h}$ transport by road and ferry on some blood indicators of welfare in lambs. Livest. Sci. 121, 132-136, https://doi. org/10.1016/j.livsci.2008.06.001

Ząbek K., Milewski S., Wójcik R., Siwicki A.K., 2013. Effect of $\beta-1,3 /$ 1,6 -D-glucan in diet on productivity and humoral and cellular defense mechanisms in sheep. Acta Vet. Brno 82, 141-146, https://doi.org/10.2754/avb201382020141

Zhang A.W., Lee B.D., Lee S.K., Lee K.W., An G.H., Song K.B., Lee C.H., 2005. Effects of yeast (Saccharomyces cerevisiae) cell components on growth performance, meat quality, and ileal mucosa development of broiler chicks. Poult. Sci. 84, 1015-1021, https://doi.org/10.1093/ps/84.7.1015 